\title{
The role of natriuretic peptide estimation in severe COVID-19
}

\author{
Kunal Mahajan, Prakash Chand Negi \\ Department of Cardiology, Indira Gandhi Government Medical College, Shimla, India
}

Since its inception in Wuhan in December 2019, Coronavirus disease 2019 (COVID-19) has shattered the economies and health-care infrastructures worldwide. Even the best of health-care systems (United States, Italy) have been overwhelmed and collapsed because of this unprecedented pandemic. India is preparing itself for the onslaught of Coronavirus. After recording its first case on January $30^{\text {th }}, 2020$, the rise was slow until the last week of March. However, since then, the number of cases has increased exponentially, and as on April $14^{\text {th }}, 2020$, there have been more than 10,000 cases of coronavirus disease (COVID-19) in India, which has resulted in more than 350 deaths.

Since this number is going to increase further in the coming days, it might overwhelm the available health-care resources. Unfortunately, Indian health-care infrastructure has its limitations and is not as developed as that of developed countries. It is yet to come in terms with the increased need for diagnostic testing kits and PPE (Personal Protective Equipment) kits. Therefore, in such a scenario, it becomes crucial for us to improvise ways and tools

Correspondence: Dr. Kunal Mahajan, Assistant Professor, Department of Cardiology, Indira Gandhi Government Medical College, Shimla 171001, HP, India.

Tel. +91.8628864820

E-mail: kunalmahajan442@gmail.com

Key words: Natriuretic peptide; coronavirus; COVID-19.

Funding: This research did not receive any specific grant from funding agencies in the public, commercial or not-for-profit sectors.

Conflicts of interest: The authors have no conflict of interest to declare.

Authors' contributions: Both the authors made substantial contributions to the conception/design of the work, acquisition, analysis, or interpretation of data, drafting the work or revising it critically for important intellectual content. Both the authors have read and approved the final version of the manuscript and agreed to be accountable for all aspects of the work.

Received for publication: 15 April 2020.

Accepted for publication: 22 April 2020.

${ }^{\circ}$ Copyright: the Author(s), 2020

Licensee PAGEPress, Italy

Monaldi Archives for Chest Disease 2020; 90:1316

doi: 10.4081/monaldi.2020.1316

This article is distributed under the terms of the Creative Commons Attribution Noncommercial License (by-nc 4.0) which permits any noncommercial use, distribution, and reproduction in any medium, provided the original author(s) and source are credited. to manage COVID-19 patients with minimal resources effectively.

COVID-19 is predominantly a respiratory illness and follows an uncomplicated course in almost $80 \%$ cases. However, in the remaining $20 \%$, it follows a severe course and is characterized by respiratory distress (respiratory rate $>30 / \mathrm{min}$, low arterial saturation, lung infiltrates), for which patients need hospital admission and oxygen inhalation. Out of these, nearly 5\% develop critical end-organ damage and need admission in intensive care units [1]. Interestingly, cardiac involvement occurs in one every five patients admitted with COVID-19, mainly in the form of myocardial damage [2]. The latter may occur due to direct virus-induced myocardial invasion and injury, or it may occur due to inflammatory stress, oxidative stress, or demand-supply mismatch. There is also an enhanced risk of acute coronary syndrome secondary to plaque rupture as a result of infection-induced increased inflammatory and hemodynamic stress in the body [2]. Furthermore, the presence of myocardial injury is a significant predictor of mortality in hospitalized COVID-19 patients [3]. The extent of myocardial injury is more significant in patients with pre-existing diabetes, hypertension, and cardiovascular disease [3].

Therefore, it becomes clinically essential to differentiate between the pulmonary and the cardiac cause of respiratory distress in patients with severe COVID-19. This differentiation will have diagnostic, therapeutic, and prognostic implications, which we believe can be reliably done by the estimation of natriuretic peptides [BNP (B-type natriuretic peptide), and NT-pro BNP (Nterminal prohormone BNP)].

However, the American College of Cardiology (ACC) recently published an advisory statement on the use of biomarkers in COVID-19 [4] It recommended that "clinicians are advised only to measure natriuretic peptides if the diagnosis of acute heart failure is suspected on clinical grounds." This recommendation was because of the non-specific nature of natriuretic peptides, which might also elevate among patients with severe respiratory illnesses even in the absence of elevated filling pressures or clinical heart failure. The ACC further recommended that elevated natriuretic peptides in patients with COVID-19 should not necessarily trigger evaluation or treatment for heart failure unless there is clear clinical evidence for the diagnosis [4].

However, we believe that with all the recommended precautions required for minimizing aerosol exposure, it is difficult for an intensivist to carefully elicit the typical clinical signs of heart failure in a severe COVID-19 patient with respiratory distress. This difficult is only going to be augmented once the hospitals are going to be full of COVID-19 patients. Furthermore, the majority of signs and symptoms of heart failure are very subjective, and even in a non-COVID associated acute respiratory distress syndrome (ARDS), it is sometimes challenging to distinguish the cause of dyspnea clinically [5]. For all the reasons mentioned above, we would need a reliable cardiac biomarker that could distinguish between cardiogenic and non-cardiogenic pulmonary edema, which could give us a reliable estimate of myocardial 
damage/dysfunction provide therapeutic and prognostic guidance, and as well as monitor the response to treatment.

Unfortunately, we do not have much data on the use of natriuretic peptides in COVID-19 patients. In a retrospective analysis of 187 hospitalized COVID-19 patients, the levels of troponin T correlated positively with NT-pro BNP levels, justifying the ability of the latter to assess myocardial damage [3]. Interestingly, on serial monitoring, the NT-pro BNP levels increased significantly during hospitalization in non-survivors, while the levels remained static in patients who survived, thus highlighting the importance of natriuretic peptides for prognostication in these patients [3]. Furthermore, In a recently published small observational study, NT-pro BNP was demonstrated as an independent risk factor of inhospital death in patients with severe COVID-19 [6].

Before this epidemic, enough evidence existed suggesting high accuracy for BNP values $>100 \mathrm{pg} / \mathrm{ml}$, and NT-proBNP value $>900$ $\mathrm{pg} / \mathrm{ml}$ in the diagnosis of acute $\mathrm{HF}$, outperforming clinical criteria [5]. However, in non-COVID settings, their primary role would be to support clinical judgment, rather than replace it. Nevertheless, in cases of severe COVID-19, which supposedly present more diagnostic indecision, these biomarkers are likely to be of great use. Importantly, normal or mildly elevated values can help in triaging by excluding the cardiac cause of dyspnea, which can further downstream the need for cardiac evaluation and echocardiography. Another potential advantage of natriuretic peptides in COVID-19 patients would be in guiding therapy. In a poor resource setting, natriuretic peptides potentially act as a substitute for invasive hemodynamic monitoring. In patients with elevated levels, it is reasonable to start diuretics, inotropes, and vasopressors. Furthermore, the serial fall or rise in levels can help to monitor/tailor the therapy.

All these potential benefits make natriuretic peptide estimation a potentially useful approach in patients with severe COVID-19 to distinguish between cardiac and pulmonary cause of dyspnea, to risk-prognosticate the patients, and to guide and monitor therapy. Further focused research is warranted to validate its role in the setting of the COVID-19 pandemic.

\section{References}

1. Thomas-Rüddel D, Winning J, Dickmann P, et al. Coronavirus disease 2019 (COVID-19): update for anesthesiologists and intensivists. Anaesthesist 2020;69:225-35. doi: 10.1007/ s00101-020-00758-x.

2. Shi S, Qin M, Shen B, et al. Association of cardiac injury with mortality in hospitalized patients with COVID-19 in Wuhan, China. JAMA Cardiol 2020. doi: 10.1001/jamacardio. 2020.0950

3. Guo T, Fan Y, Chen M, et al. Cardiovascular implications of fatal outcomes of patients with coronavirus disease 2019 (COVID-19). JAMA Cardiol 2020. doi: 10.1001/jamacardio. 2020.1017

4. American College of Cardiology. Troponin and BNP use in COVID-19. Accessed on: 13 April 2020. Available from: https://www.acc.org/latest-in-cardiology/articles/2020/03/ 18/15/25/troponin- and-bnp-use-in-covid19

5. Komiya K, Akaba T, Kozaki Y, et al. A systematic review of diagnostic methods to differentiate acute lung injury/acute respiratory distress syndrome from cardiogenic pulmonary edema. Crit Care 2017;21:228. doi: 10.1186/s13054-0171809-8.

6. Gao L, Jiang D, Wen X, et al. Prognostic value of NT-proBNP in patients with severe COVID-19. Respir Res 2020;21:83. doi: 10.1186/s12931-020-01352-w. 